\title{
Chk1 inhibition as a novel therapeutic strategy in melanoma
}

\author{
Bor-Jang Hwang ${ }^{1,2}$, Gautam Adhikary ${ }^{1}$, Richard L. Eckert ${ }^{1,2,3,4}$ and A-Lien Lu ${ }^{1,2}$ \\ ${ }^{1}$ Department of Biochemistry and Molecular Biology, University of Maryland School of Medicine, Baltimore, MD, USA \\ ${ }^{2}$ University of Maryland Greenebaum Comprehensive Cancer Center, Baltimore, MD, USA \\ ${ }^{3}$ Department of Dermatology, University of Maryland School of Medicine, Baltimore, MD, USA \\ ${ }^{4}$ Department of Reproductive Biology, University of Maryland School of Medicine, Baltimore, MD, USA \\ Correspondence to: A-Lien Lu, email: alu-chang@som.umaryland.edu \\ Keywords: BRAF; Chk 1; inhibitors; drug resistance; melanoma
}

Received: May 13,2018 Accepted: June 28, $2018 \quad$ Published: July 13, 2018

Copyright: Hwang et al. This is an open-access article distributed under the terms of the Creative Commons Attribution License 3.0 (CC BY 3.0), which permits unrestricted use, distribution, and reproduction in any medium, provided the original author and source are credited.

\section{ABSTRACT}

Melanoma patients respond poorly to chemotherapies because they acquire drug resistance. Therapies that can overcome the resistance to inhibitors of the mutated BRAF protein kinase in melanoma are urgently needed. Chk1 protein kinase is a central component of the DNA damage response and plays a crucial role in controlling cell cycle progression. Analyses indicate that low mRNA expression of Chk1 is significantly associated with good overall survival of melanoma patients. To evaluate the effectiveness of Chk1 inhibitors in melanoma therapy, we have generated BRAF inhibitor (PLX4032 or vemurafenib) resistant melanoma cell lines (A375-PLX-R and WM9-PLX-R) from A375 and WM9, respectively. We observe that AKT (protein kinase $B$ ) is constitutively activated in A375-PLX-R, but not in WM9-PLX-R cells, suggesting that these cells develop resistance to PLX4032 through different mechanisms. We show that a potent and specific inhibitor of Chk1 (PF477736) is effective in reducing cell viability and colony formation of PLX4032-resistant cells. Even more impressively, PF477736 triggers PLX4032-resistant melanoma cells to regain sensitivity to the PLX4032. Mouse xenograft studies show that treating A375-PLX-R derived tumors with combined PLX4032 and PF477736 significantly reduce tumor growth. Combined treatments with PLX4032 and PF477736 reduce the levels of total Chk1 protein and alter Chk1 phosphorylation at several sites in both PLX4032 sensitive and resistant melanoma cells. Combinatorial treatments with PLX4032 and PF477736 to melanoma cells substantially induce DNA damage and cell death. Our results suggest that Chk1 inhibitors may provide new therapy options for melanoma patients.

\section{INTRODUCTION}

Melanoma is the deadliest form of skin cancer and has a strong tendency to metastasize with a poor prognosis for survival [1]. The conversion of melanocytes to melanoma cells is frequently accompanied by alterations in key signaling pathways [2]. The Ras pathways are activated by many different stimuli through binding to the membrane receptors [3]. Ras then activates RAF (BRAF and CRAF) and PI3K (phosphatidylinositol 3-kinase). RAF kinases phosphorylate MEK (mitogen-activated protein kinase) which then activates ERK (extracellular signal-regulated kinase). PI3K promotes while PTEN (phosphatase and tensin homology) inhibits the activities of downstream PDK1 (3-phosphoinositide-dependent protein kinase-1) and AKT (or PKB, protein kinase B). Activation of these pathways leads to cell proliferation and survival. Approximately $60 \%$ of melanomas contain a V600E mutation in the $B R A F$ gene $[4,5]$. Constitutive activation of the ERK pathway caused by $\mathrm{BRAF}^{\mathrm{V} 600 \mathrm{E}}$ mutation accompanied by loss of PTEN tumor suppressor is the most common cause of melanomagenesis $[4,6]$. 
Targeted therapy against BRAF mutation represents one of the most significant advances in the treatment of melanoma (reviewed in [7]). Vemurafenib (PLX4032), a specific BRAF inhibitor (BRAFi), has been approved to treat late-stage melanoma with $\mathrm{BRAF}^{\mathrm{V} 600 \mathrm{E}}$ mutation [8]. While PLX4032 targets melanoma with high efficacy and selectivity, the duration of response is usually limited (about 6 months) $[7,9,10]$. Thus, novel strategies to treat BRAFi-resistant melanoma are urgently needed.

Chk1 kinase is a central component of the DNA damage response and plays a crucial role in controlling cell cycle progression [11]. The DNA damage response pathway is activated to elicit both DNA repair processes and cell cycle arrest (which allows time for DNA repair). When DNA damage is extreme, apoptosis is triggered [11, 12]. Chk1 phosphorylation at S317 and S345 by ataxia telangiectasia and Rad3-related protein (ATR) is essential for cell-cycle checkpoint control [13, 14]. During DNA damage response, Chk1 autophosphorylation at S296 after phosphorylation by ATR $[15,16]$ is critical for cell cycle arrest [17]. Recent studies have shown that Chk1 can be phosphorylated by CDK and AKT at different residues, affecting subcellular localization [17, 18]. At G0/G1 transition, Chk1 is phosphorylated at S280 by Ras/ mitogen-activated 90-kDa ribosomal S6 kinase (p90 RSK) [19] and translocated from the cytoplasm to the nucleus. However, in response to DNA damage during the G2 phase, Chk1 phosphorylation at S280 by AKT reduces nuclear localization and impairs DNA damage response [20-22]. Cell cycle checkpoints are promising targets for anticancer therapies because they control cancer cell responses to anticancer agents [23, 24]. Chk1 inhibitors (Chk1i) have emerged as very effective therapeutic agents alone and in combinatorial therapies [25-29]. PF477736, a potent and specific inhibitor of Chk1 (with $\approx 100$-fold selectivity over Chk2) [28, 30], potentiates the antitumor activity of gemcitabine [30] and is in phase 1 clinical trials with gemcitabine $[23,24]$. In this report, we find that PF477736 significantly retards melanoma cell growth, but even more impressively, triggers PLX4032-resistant melanoma cells re-sensitizing to PLX4032. We suggest that Chk1i may prevent the development of BRAFi resistance in melanoma because Chk1 inhibition can cause cancer cells to arrest improperly with damaged DNA and undergo apoptosis.

\section{RESULTS}

\section{Chk1 is a biomarker of melanoma prognosis}

Chk1 kinase is required to manage DNA repair, DNA replication, and cell cycle progression in cancer cells $[11,31]$. Several Chk1i have been demonstrated to reduce the cell viability of melanoma cells [32-34]. To examine whether Chk1i are effective for melanoma patients, we analyzed the survival of melanoma patients from an online database [35] using Chk1 mRNA expression as a marker. By analyzing 44 melanoma patients of the Bogunovic data set, we observed that low mRNA expression of Chk1 is significantly associated with good overall survival of melanoma patients [hazard ratio (HR) is 3.17; $P=0.012]$ (Figure 1A). The 50\% survival time of low Chk1 expression patients is $\approx 19$ months longer than that of high Chk1 expression patients. Analysis of 335 melanoma patients in the SKCM-TCGA data set also indicates that low mRNA expression of Chk1 is associated with good overall survival of melanoma patients (HR is 1.33; $P=0.063$ ) (Figure 1B). The 50\% survival time of low Chk1 expression patients is $\approx 33$ months longer than that of high Chk1 expression patients. These results have implications for employing Chk1 inhibitors in melanoma treatment.

\section{Development of PLX4032-resistant melanoma cell lines}

To compare the effectiveness of Chk1 inhibitors on different melanoma cells, we generated BRAF inhibitor PLX4032 resistant melanoma cell lines (A375-PLX-R and WM9-PLX-R) from A375 and WM9 respectively. These cell lines are $\mathrm{p} 53$ positive, but have different expression of the PTEN tumor suppressor. A375 cell line is PTENpositive while WM9 cell line does not express PTEN protein due to homozygous deletion of the PTEN gene [36]. PTEN has been shown to play a direct role in DNA repair [37, 38] and DNA damage response [39] through interaction with Chk1 and the tumor suppressor p53. Thus, PTEN status may influence cellular response to Chk1 inhibitors.

The A375-PLX-R cells have been shown to have altered Hippo pathways [40]. Because melanoma can develop BRAFi resistance by activating alternative survival pathways $[7,9,10]$, we examined whether the Ras pathways are altered in A375-PLX-R and WM9PLX-R cells. The ratio of P-ERK/total ERK is increased in untreated A375-PLX-R (Figure 2, compare P-ERK/ERK in lanes 1 and 3). However, the ratio of P-ERK/total ERK is decreased in untreated WM9-PLX-R (Figure 2, compare P-ERK/ERK in lanes 5 and 7). AKT is constitutively activated in untreated A375-PLX-R (Figure 2, P-AKT in lanes 1 and 3), but not in untreated WM9-PLX-R cells as compared to their parental cell lines (Figure 2, P-AKT in lanes 5 and 7). We then analyzed the alterations of the Ras pathways by treating the cells transiently with $7.5 \mu \mathrm{M}$ PLX4032 for $6 \mathrm{~h}$ which did not lead to massive cell death. As expected, phosphorylated ERK1/2 is absent in A375 and WM9 cells (Figure 2, lanes 2 and 6 for P-ERK1/2) following PLX4032 treatment. Treated A375-PLX-R cells also have no detectable phosphorylated ERK1/2 (Figure 2, P-ERK1/2 in lane 4), but treated WM9-PLX-R cells contain $\approx 32 \%$ level of phosphorylated ERK $1 / 2$ as compared with untreated cells (Figure 2, compare lanes 7 and 8 for P-ERK/ERK ratio). The ratio of P-AKT/ 
total AKT is unchanged in PLX4032-treated A375 and A375-PLX-R cells (Figure 2, compare P-AKT/AKT in lanes 1-4). The ratio of P-AKT/total AKT is increased in PLX4032-treated WM9, but decreased in treated WM9PLX-R cells (Figure 2, compare P-AKT/AKT in lanes 5-8). These data suggest that these two PLX4032-resistant cell lines develop resistance to PLX4032 through different mechanisms.

\section{PF477736 is an effective therapeutic agent to melanoma cells}

We then examined the response of both A375 and A375-PLX-R melanoma cells to a potent Chk1 inhibitor (PF477736) which has higher specificity over Chk2 $\left(\mathrm{IC}_{50}=0.49 \mathrm{nM}\right.$ for Chk1 and $\mathrm{IC}_{50}=47 \mathrm{nM}$ for Chk2) $[28,30]$ and has been in phase 1 clinical trials with gemcitabine [23, 24]. Figure $3 \mathrm{~A}$ and $3 \mathrm{~B}$ show that both cell lines are sensitive to Chk1i. PF477736 is more effective in inhibiting cell viability (Figure 3A) and colony formation (Figure 3B) of A375-PLX-R than A375 cells ( $\mathrm{IC}_{50}$ of viability for A375 and A375-PLX-R are 1.4 and $0.4 \mu \mathrm{M}$, respectively). These results suggest that Chk1 function is more important for the cell survival of A375PLX-R than A375 cells.

We then tested whether the effect of Chk1i could be extended to PTEN-negative WM9 and its derived PLX4032-resistant cells. Figure 3C and 3D show that both cell lines are also sensitive to Chk1i. However, PF477736 is more effective in inhibiting cell viability (Figure 3C) and colony formation (Figure 3D) of WM9 than WM9PLX-R cells ( $\mathrm{IC}_{50}$ of viability for WM9 and WM9-PLX-R are 1.0 and $4.0 \mu \mathrm{M}$, respectively). Thus, in contact to A375 cell lines, Chk1 function is less important for the cell survival of WM9-PLX-R than WM9 cells.

\section{PF477736 re-sensitizes PLX4032-resistant melanoma cells to PLX4032}

The response to PLX4032 is not durable because many patients acquire drug resistance $[9,10]$. Thus, we examined whether Chkli can potentiate the potency of PLX4032 in melanoma. We treated the melanoma cells with Chk1i (PF477736, 0.15 $\mu \mathrm{M}$ ) in combination with increasing concentrations of BRAFi (PLX4032, 0-20 $\mu \mathrm{M})$. At this low concentration of PF477736, the growth of both A375 and A375-PLX-R cells is only slightly inhibited (Figure 3 ). Our results indicate that the cell viability of A375 cells is only synergistically inhibited by $0.15 \mu \mathrm{M}$ PF477736 and high concentrations (12.5-20 $\mu \mathrm{M}$ ) of PLX4032 (Figure 4A). However, both inhibitors have synergy in inhibiting the cell viability of A375-PLX-R cell at all tested PLX4032 concentrations (Figure 4B). In colony formation assay, small synergy of PF477736 and PLX4032 was observed with A375 cell (Figure 4C). In contrast to cell viability, A375PLX-R cells form more colonies in the presence of 2.5-15 $\mu \mathrm{M}$ PLX4032 than in its absence (compare Figure 4B and 4D, green curves), indicating A375-PLX-R cells are addicted to PLX4032 during 10-day colony formation culture. Strikingly, there are fewer colonies in PF477736+PLX4032 than in PF477736 treatment alone at all tested PLX4032 concentrations (Figure 4D, purple curve). Representatives of colony formation of
A

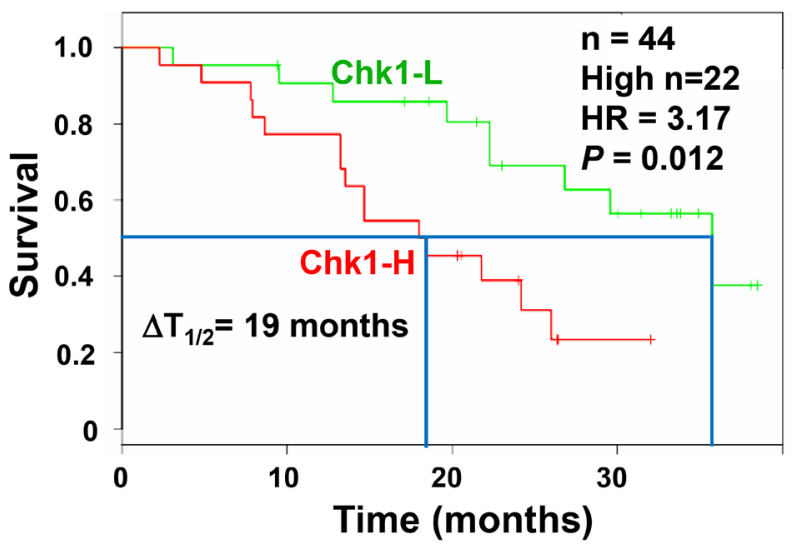

B

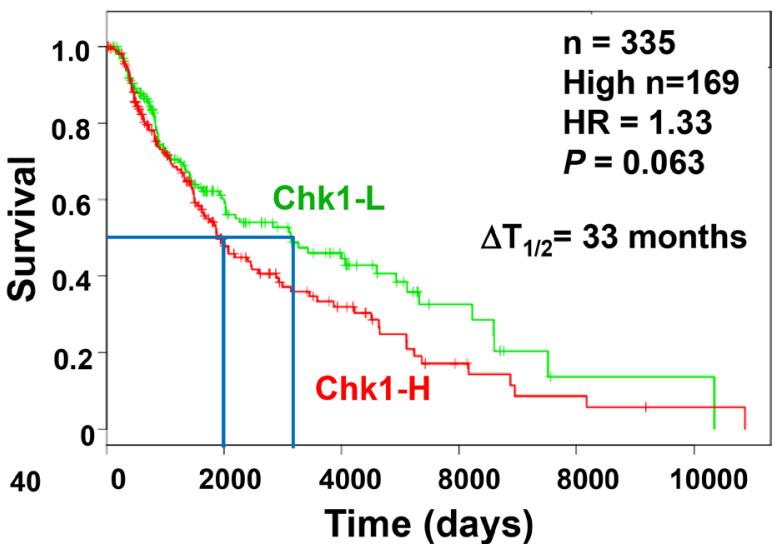

Figure 1: High Chk1 expression is associated with poor prognosis of melanoma. The Kaplan-Meier plots for the survival of melanoma patients are constructed from an online database [35] using Chk1 mRNA expression as a marker. (A) There are 44 melanoma patients in the Bogunovic database and 22 have high Chk1 mRNA expression. We observed that low mRNA expression of Chk1 is significantly associated with good overall survival of melanoma patients [hazard ratio $(\mathrm{HR})=3.17 ; P=0.012$ ]. The $50 \%$ survival time $\left(\mathrm{T}_{1 / 2}\right)$ of low Chk1 expression patients is $\approx 19$ months longer $\left(\Delta \mathrm{T}_{1 / 2}\right)$ than that of high Chk1 expression patients. (B) Total melanoma patients in the SKCM-TCGA database are 335 with 169 having high Chk1 mRNA expression. Low mRNA expression of Chk1 is also associated with good overall survival of melanoma patients [HR $=1.33 ; P=0.063 ; \Delta \mathrm{T}_{1 / 2} \approx 33$ months]. 
Figure 4C and 4D are shown in Figure 5A and 5B. Data from more than three experiments with $10 \mu \mathrm{M}$ of PLX4032 and $0.15 \mu \mathrm{M}$ of PF477736 are shown in Figure 5C. This result indicates that the PLX4032-resistant A375-PLX-R cell are sensitized to PLX4032 in the presence of PF477736 or that A375-PLX-R cell are more sensitive to PF477736 in the presence of PLX4032.

Combinatorial treatments with PF477736 (0.5 $\mu \mathrm{M})$ and PLX4032 $(2.5-10 \mu \mathrm{M})$ also synergistically inhibit the cell viability of WM9-PLX-R cells (Figure 6B), but not of WM9 cells (Figure 6A). In the colony formation assay, small synergy of PF477736 and PLX4032 was observed with WM9 cell (Figure 6C and Figure 6E). In contrast to A375-PLX-R cells, WM9-PLX-R cells show no addiction to PLX4032 during 10-day colony formation culture (compare Figure 5B and Figure 6D). However, similar to A375-PLX-R cells, WM9-PLX-R cells regain the sensitivity to PLX4032 in the presence of PF477736 for all tested PLX4032 concentrations (Figure 6D and Figure 6E). Taken together, results from our studies indicate that combinatorial treatments with BRAFi and Chk1i synergistically reduce cell viability and colony formation of PLX4032-resistant melanoma cells. This indicates that Chk1 inhibitors can re-sensitize BRAFiresistant melanoma cells to BRAFi.

\section{Co-treatment with PLX4032 and PF477736 suppresses tumor formation}

We next examined the influence of Chk1i on the ability of melanoma cancer stem (MCS) cells (selected as spheroids on ultra-low attachment dishes) to form tumors on female nude mice. We select A375-PLX-R MCS for tumor studies because they are the most aggressive cells [40]. We injected 100,000 A375-PLX-R MCS cells into each front flank of nude mice and monitored tumor formation with drug treatments initiated at the time of tumor cell injection. Figure 7 shows that tumors appear at 3-week post-injection. The mice receiving PF477736 alone and PF477736+PLX4032, but not PLX4032 alone, have substantially smaller tumors than the controls after week 5 and week 6 that is more significant in co-treated tumors. This finding suggests that Chk1 inhibition may be an effective anticancer strategy in PLX4032-resistant melanoma.

\section{Chk1 inhibition regulates Chk1 phosphorylation}

In DNA damage response, Chk1 arrests cell cycle progression following genotoxic stress and stalled replication to prevent the entry of cells with damaged

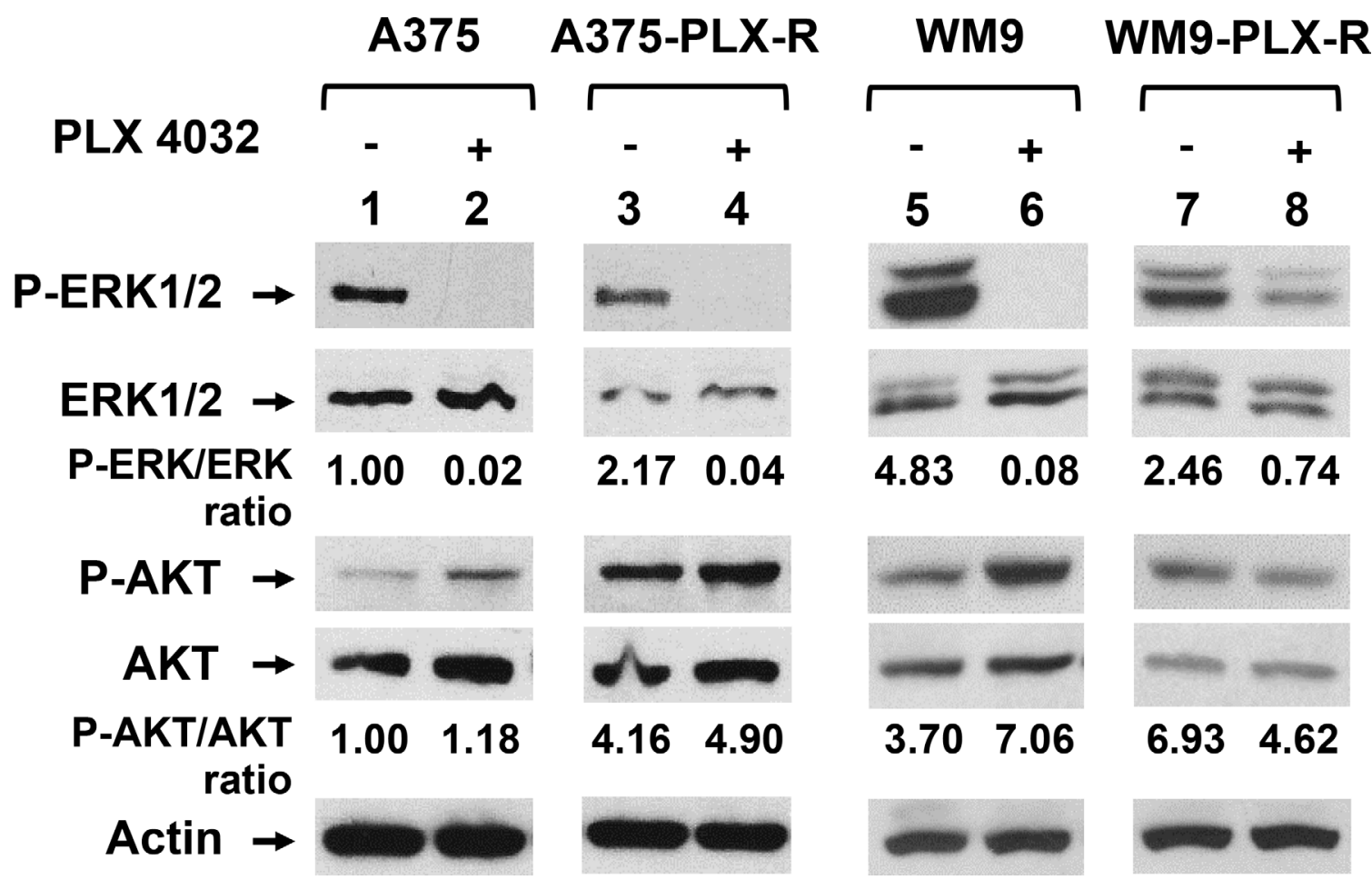

Figure 2: PLX4032-resistant melanoma cells have altered Ras signal pathways. A375-PLX-R and WM9-PLX-R are derived from A375 and WM9, respectively. Cells were treated with $7.5 \mu \mathrm{M}$ PLX4032 for $6 \mathrm{~h}$ or left untreated. Cell extracts were prepared and about $25 \mu \mathrm{g}$ of total protein were separated on 10-16\% SDS-polyacrylamide gels and transferred to nitrocellulose membranes for Western blotting analysis with respective antibodies. The images were quantitated as described in MATERIALS AND METHODS. Ratios of phosphorylated proteins (P-ERK1/2 and P-AKT) over total proteins were calculated and then adjusted relative to the value of lane 1 (untreated A375 cells). Values of relative ratios presented are the averages of images from two independent experiments. 
DNA into mitosis [11]. In addition to its role in the DNA damage response, Chk1 also controls the initiation of DNA replication, stabilization of replication forks, and coordination of mitosis and DNA repair [24]. It is unclear whether Chkli disrupts one or all of these pathways to inhibit melanoma growth. It is also not clear why PLX4032-resistant melanoma cells regain the sensitivity to PLX4032 in the presence of Chk1i (Figures 4-7). Thus, we attempted to reveal the underlying mechanisms.

Chk1 is phosphorylated at S317 and S345 by ATR protein kinases in response to DNA damage to regulate cell cycle progression [41, 42]. After phosphorylation by ATR at S317 and S345, Chk1 can autophosphorylate itself at S296 [15, 16]. Surprisingly, it has been reported that inhibition of Chk1 kinase activity leads to hyperphosphorylation of Chk1 at S317 and S345 in cancer cells $[31,43]$. It has been shown that ATR-mediated Chk1 phosphorylation is antagonized by a Chk1regulated protein phosphatase 2A circuit [43]. Hyperphosphorylation of Chk1 at S317 and S345 has been used as an indicator of Chk1 inhibition [31]. Thus, we determined the levels of Chk1 phosphorylation in the four melanoma cells following transient treatments with
PLX4032 (7.5 $\mu \mathrm{M})$ and/or PF477736 (0.15 $\mu \mathrm{M})$ for $6 \mathrm{~h}$. Western blotting analyses indicate that the total Chk1 protein level is increased in untreated A375-PLX-R cells (Figure 8A) but decreased in untreated WM9-PLX-R cells (Figure $8 \mathrm{~B}$ ) as compared to their parental cell lines. Drug treatments only slightly alter the total Chk1 protein levels in all four cell lines. The level of Chk1 phosphorylation at S296 is greatly reduced when all four cell lines are treated with PF477736 or PLX4032+PF477736, indicating that PF477736 blocks Chk1 activity in vivo (Figure 8A, see ratios of P-S296/Chk1). When A375, WM9, and WM9PLX-R cell lines are treated with PLX4032 alone, the level of Chk1 phosphorylation at S296 is slightly reduced. Our data indicate that the levels of Chk1 phosphorylation at S296 is reversely proportional to the levels of Chk1 phosphorylation at S317 and S345 (Figure 8A and 8B). The levels of Chk1 Ser317 and S345 phosphorylation are elevated when all four cell lines are treated with PF477736 or PLX4032+PF477736, but not with PLX4032 single treatment (Figure 8A and 8B, see ratios of P-S317/ Chk1 and P-S345/Chk1). Combinatorial treatments with PLX4032 and PF477736 for $6 \mathrm{~h}$ induced the highest extents of Chk1 S317 and S345 phosphorylation in A375,

\section{A Cell viability}

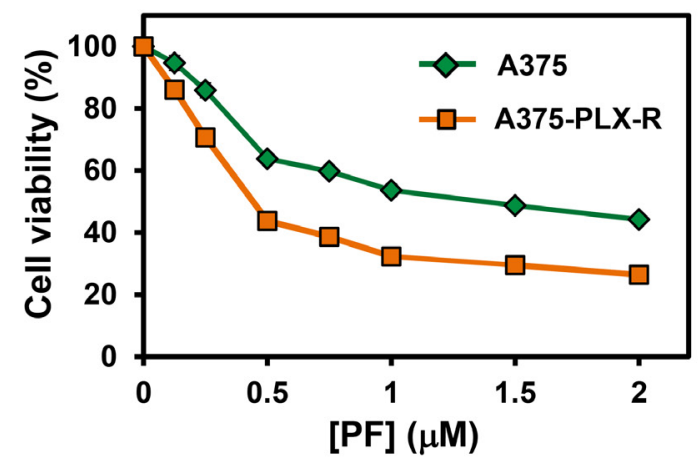

\section{Cell viability}

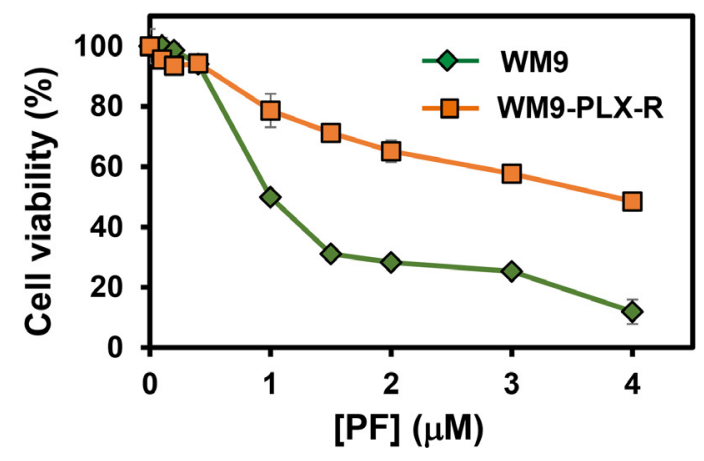

\section{B Colony formation}

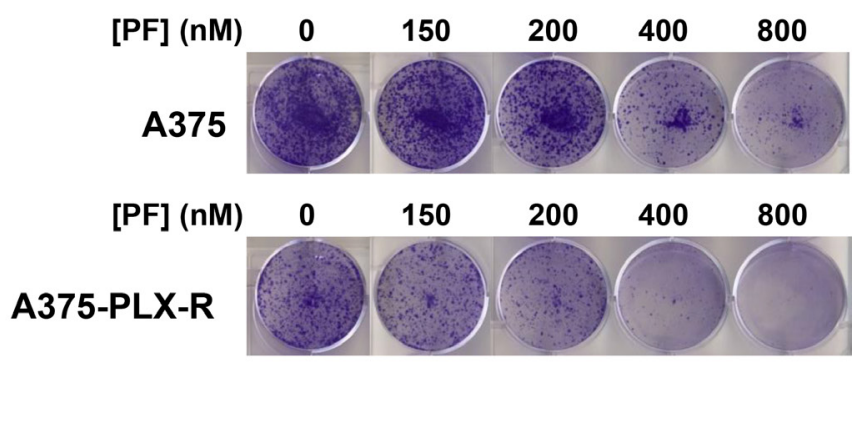

D Colony formation

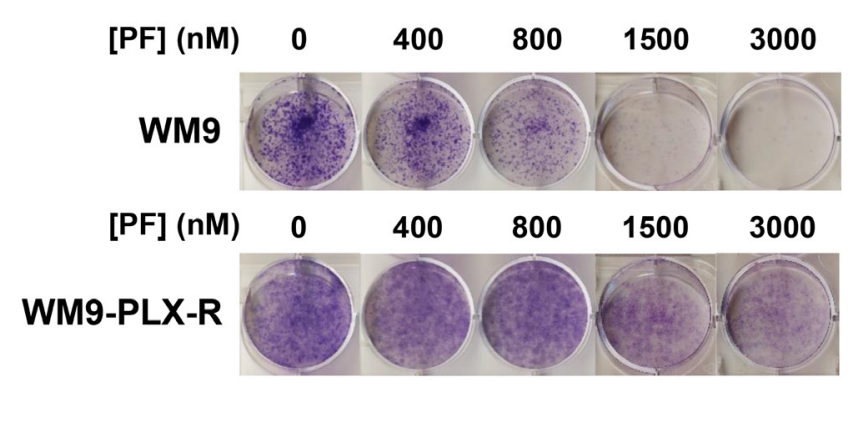

Figure 3: Response of melanoma cells to Chk1 inhibitor PF477736. (A) and (B) A375-PLX-R melanoma cell is more sensitive to PF477736 than A375 in both cell viability and colony formation assays. (C) and (D) WM9-PLX-R melanoma cell is less sensitive to PF477736 than WM9 in both cell viability and colony formation assays. One-day post-seeding, the cells were treated with various concentrations of PF477736 or DMSO for $48 \mathrm{~h}$. Cell viability and colony formation were measured as described in MATERIALS AND METHODS. The error bars reported in (A) and (C) are the standard deviations of the averages from triplicates of three independent experiments. 
WM9, and WM9-PLX-R cells, but not in A375-PLX-R cells (Figure 8A and 8B, see ratios of P-S317/Chk1 and P-S345/Chk1).

To study the duration of drug effects, we also determined Chk1 alterations in A375 and A375-PLX-R cells following treatments with PLX4032 (7.5 $\mu \mathrm{M})$ and/or PF477736 $(0.15 \mu \mathrm{M})$ for $16 \mathrm{~h}$. Compared to $6 \mathrm{~h}$ treatments, the total Chk1 protein levels are substantially reduced in both cell lines following treatments with PLX4032 and PLX4032+PF477736 for 16 h (Figure 8C, Chk1 lanes 1-8). Thus, PLX4032 treatment can reduce Chk1 protein expression and its effect is enhanced by the presence of PF477736. Similar to $6 \mathrm{~h}$ treatment, the level of Chk1 phosphorylation at S296 is greatly reduced when A375 and A375-PLX-R cells are treated with PF477736 or PLX4032+PF477736 (Figure 8C, see ratios of P-S296/Chk1). When A375 cell lines are treated with PLX4032 alone, the level of Chk1 phosphorylation at S296 is also reduced. The levels of Chk1 S317 and S345 phosphorylation are induced most in PLX4032+PF477736treated A375-PLX-R cells (Figure 8C, see ratios of P-S317/ Chk1 and P-S345/Chk1). Thus, the phosphorylation levels of Chk1 at S317 and S345 in A375-PLX-R cells are higher at $16 \mathrm{~h}$ than $6 \mathrm{~h}$ following combinatorial treatment with PLX4032 and PF477736 (compare Figure 8A and 8C).

Next, we examined the drug effects on Chk1 phosphorylation at $\mathrm{S} 280$ which is carried out by $\mathrm{p} 90$ RSK at G0/G1 transition [19] or by AKT1 in response to DNA damage during the G2 phase [20-22]. Chk1 phosphorylation at $\mathrm{S} 280$ by these Ras downstream kinases alters Chk1 localization between the cytoplasm and the nucleus and affects checkpoint activation. The level of Chk1 S280 phosphorylation is unchanged in untreated A375-PLX-R cells (Figure 8A) but decreased in untreated WM9-PLX-R cells as compared to their parental cell lines (Figure 8B). The levels of Chk1 S280 phosphorylation are diminished when A375 and WM9 cell lines are treated with PLX4032 or
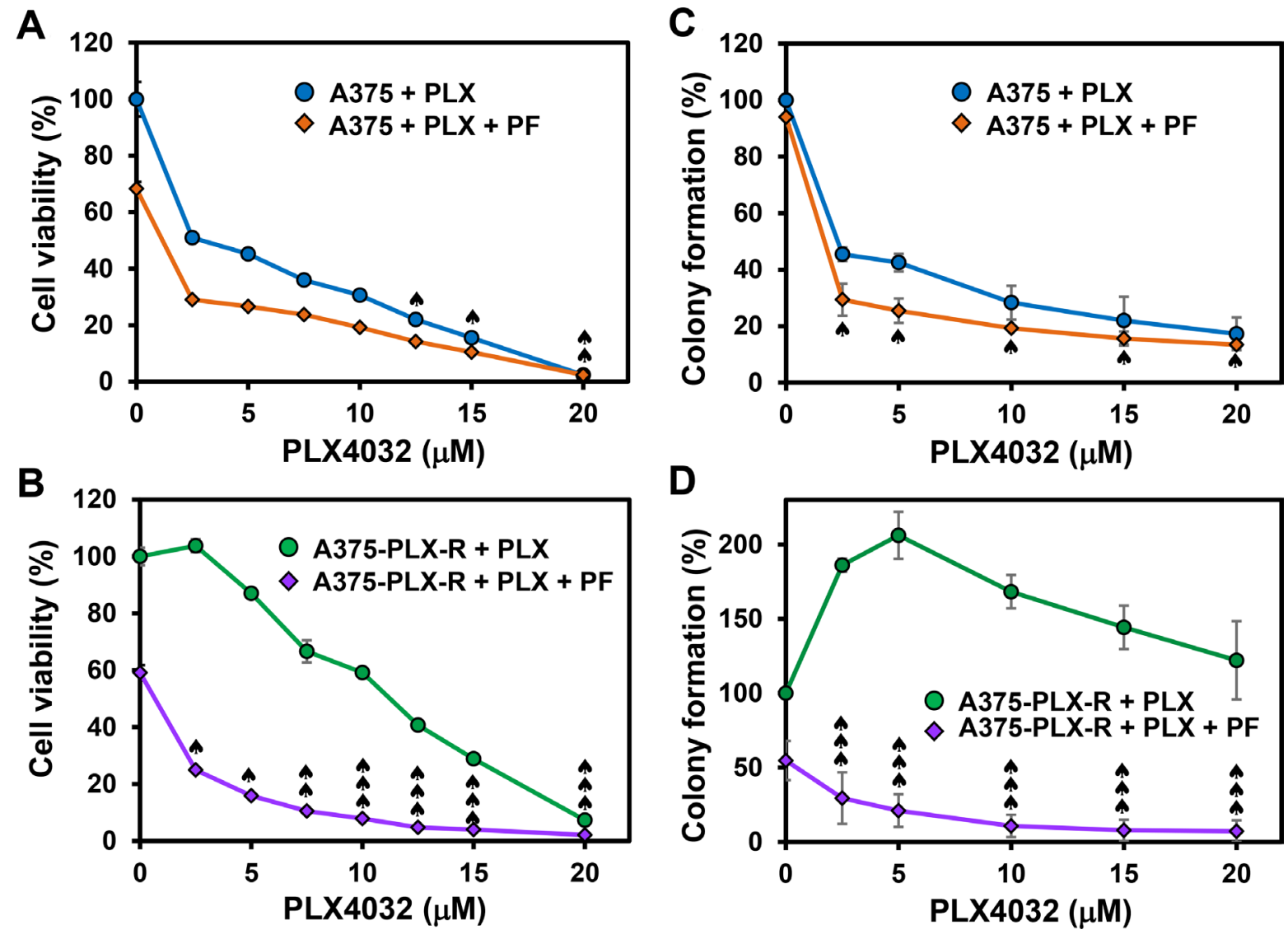

Figure 4: Chk1 inhibitor PF477736 re-sensitizes PLX4032-resistant melanoma cells to PLX4032. The melanoma cells were treated with Chk1i (PF477736, $0.15 \mu \mathrm{M})$ in combination with increasing concentrations of BRAFi (PLX4032, 0-20 $\mu \mathrm{M})$ as indicated on the X-axis. Cell viability ( $\mathbf{A}$ and $\mathbf{B}$ ) and colony formation $(\mathbf{C}$ and $\mathbf{D})$ were measured as described in MATERIALS AND METHODS. A375-PLX-R cells form more colonies in the presence of 2.5-15 $\mu \mathrm{M}$ PLX4032 than in the absence of PLX4032 (Figure 4D, green curve). The error bars reported are the standard deviations of the averages from triplicates of three independent experiments. Combination index (CI) for cells treated with two drugs was determined by CompuSyn software for Chou and Talalay analysis as described [54]. One, two, and three represent CI (0.5-0.9), CI (0.25-0.5), and CI $(<0.25)$, respectively. 
PLX4032+PF477736 for $6 \mathrm{~h}$ (Figure 8A and 8B). However, the levels of Chk1 S280 phosphorylation in A375-PLX-R and WM9-PLX-R cell lines are substantially reduced only following PLX4032+PF477736 treatment for $6 \mathrm{~h}$ (Figure $8 \mathrm{~A}$ and 8B, see ratio of P-S280/Chk1). The reduction of Chk1 S280 phosphorylation is more pronounced when A375-PLX-R cells are treated with PLX4032 or PLX4032+PF477736 for 16 h (Figure 8C, see ratio of $\mathrm{P}-\mathrm{S} 280 / \mathrm{Chk} 1)$. Combinatorial treatments to PLX4032-resistant cells synergistically reduce Chk1 S280 phosphorylation. For example, the ratios of P-S280/Chk1 are 1.8, 0.6, 1.9, and 0.1 in untreated, PLX4032-treated, PF477736-treated, and double-treated A375-PLX-R cells. Taken together, combinatorial treatments with PLX4032 and PF477736 reduce the levels of total Chk1 protein and Chk1 phosphorylation at S280 and S296, but increases the levels of Chk1 phosphorylation at S317 and S345 in both PLX4032 sensitive and resistant melanoma cells.

\section{Chk1 inhibition induces DNA damage and apoptosis}

To further investigate the mechanisms by which Chk1i boosts BRAFi sensitivity in BRAFi-resistant melanoma, we analyzed parameters of DNA damage and apoptosis. To assess the effect of Chk1i on DNA damage, we measured the levels of phosphorylated $\mathrm{H} 2 \mathrm{AX}$ $(\gamma \mathrm{H} 2 \mathrm{AX})$ which is an indication of stalled replication forks and double-strand breaks $[44,45]$. The levels of $\gamma \mathrm{H} 2 \mathrm{AX}$ are elevated when A375 and WM9 cell lines are treated with PLX4032 or PF477736 individually and are further enhanced following PLX4032+PF477736 treatment for $6 \mathrm{~h}$ (Figure $8 \mathrm{~A}$ and $8 \mathrm{~B}$ ). Following treatments with PLX4032+PF477736 for $6 \mathrm{~h}$, A375-PLX-R and WM9PLX-R cell lines also induce $\gamma \mathrm{H} 2 \mathrm{AX}$, but at a lower extent as compared with their parental cell lines. The patterns of $\gamma \mathrm{H} 2 \mathrm{AX}$ in A375 and A375-PLX-R cells following 16 $\mathrm{h}$ drug treatments are similar to those following $6 \mathrm{~h}$ drug treatments (compare Figure 8A and 8C) except the $\gamma \mathrm{H} 2 \mathrm{AX}$ level is slightly lower in PF477736-treated than untreated A375-PLX-R cells. Nevertheless, the level of $\gamma \mathrm{H} 2 \mathrm{AX}$ is synergistically elevated when all melanoma cell lines are treated by PLX4032+PF477736.

To monitor the effect of Chk1i on apoptosis, we measured the levels of cleaved PARP1, a hallmark of caspase-dependent apoptosis [46]. The level of cleaved PARP1 of A375 cells is elevated following PLX4032 treatment for $6 \mathrm{~h}$ and is further enhanced following PLX4032+PF477736 treatment, but is not increased by PF477736 single treatment (Figure 8A). There are little changes in the levels of cleaved PARP1 when A375-PLX-R, WM9, and WM9-PLX-R cells are treated with PLX4032 and/or PF477736 for 6 h. However, the levels of cleaved PARP1 of A375-PLX-R cells are elevated following PLX4032 treatment and is further enhanced following PLX4032+PF477736 treatment for $16 \mathrm{~h}$ (Figure 8C). This suggests that induction of caspase-dependent apoptosis is delayed in PLX4032and PLX4032+PF477736-treated A375-PLX-R cells. PF477736 single treatments for either $6 \mathrm{~h}$ or $16 \mathrm{~h}$ to all four cell lines do not induce PARP1 cleavage (Figure 8). Taken together, these results indicate that combinatorial

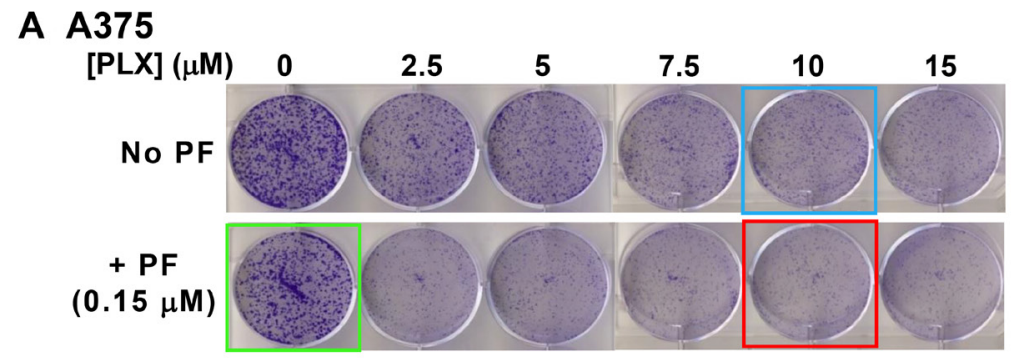

B A375-PLX-R

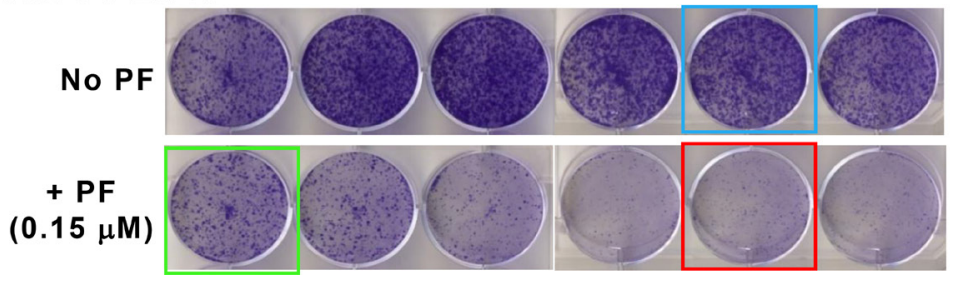

C

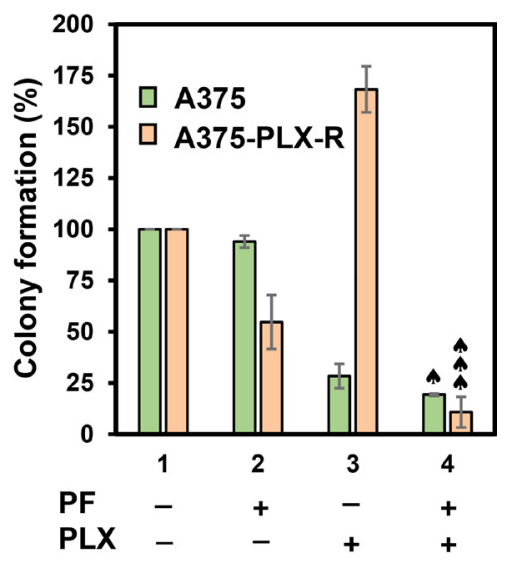

Figure 5: Colony formation of A375 (A) and A375-PLX-R (B) cells in the presence of BRAFi PLX4032 and/or Chk1i PF477736. Top panels in both (A) and (B) are cells treated with different concentrations of PLX4032 alone as indicated and bottom panels are cells treated with respective PLX4032 concentrations plus $0.15 \mu \mathrm{M}$ PF477736 for 2 days or left untreated. The cells were recovered in regular media for 10 days and colonies were counted. Data from more than three experiments with $10 \mu \mathrm{M}$ of PLX4032 (blue boxed), $0.15 \mu \mathrm{M}$ of PF477736 (green boxed), and PLX4032+PF477736 (red boxed) are shown in (C). The error bars, CI calculation, and symbol were similar to those as described in Figure 4. 
treatment with PLX4032 and PF477736 induces DNA damage and cell death pathways in melanoma cells.

\section{DISCUSSION}

BRAF inhibitor PLX4032 (vemurafenib) is very effective in treating malignant melanoma patients with $\mathrm{BRAF}^{\mathrm{V} 600 \mathrm{E}}$ mutation (reviewed in [7]). However, response to PLX4032 is not durable because many patients acquire drug resistance $[9,10]$. In this report, we have developed a novel strategy to overcome such resistance. Cell cycle checkpoints are favorable targets for anticancer therapies because they control cancer cell responses to chemotherapy and radiation [23, 24]. Although Chk1 inhibitors have been demonstrated to reduce the cell viability of melanoma cells [32-34], the efficacy of Chk1 inhibitors in melanoma therapy required further studies. Here, we show that a specific Chk1i PF477736 can overcome the resistance to PLX4032 of PLX4032-resistant melanoma cells. Although PF477736 has 100-fold specificity to Chk1 over Chk2 [28, 30], we cannot rule out it may also inhibit Chk2 in our assays. Our results demonstrate that PF477736 and PLX4032 can synergistically inhibit the cell viability and colony formation of PLX4032resistant melanoma cells. Moreover, Chk1i and combined Chk1i+BRAFi can reduce the growth of BRAFi-resistant melanoma tumor in mouse xenografts. Currently, the agents used in combination with Chk1i to treat cancers are all antimetabolites (such as cisplatin and gemcitabine) that damage DNA or interfere with DNA synthesis. Our results represent the first successful application using Chk1i and a non-antimetabolite BRAFi. The significance of our studies is justified by our Kaplan-Meier analyses (Figure 1) of more than 40 melanoma patients, indicating that low mRNA expression of Chk1 is significantly associated with good overall survival of melanoma patients. Thus, Chk1 inhibitors combined with BRAFi may provide anticancer therapeutics to current treatment regimens for BRAFiresistance melanoma patients.

We have tested the effect of Chk1i on two melanoma cell lines (A375 and WM9) and their derived PLX4032resistant cell lines. The two PLX4032-resistant cell lines, which are p53 positive but have different PTEN status, develop resistance to PLX4032 through different mechanisms. AKT is constitutively activated in A375PLX-R but not in WM9-PLX-R cells. After transient treatment with $7.5 \mu \mathrm{M}$ PLX4032 for $6 \mathrm{~h}$, ERK pathway is completely inhibited in A375-PLX-R cells but is partially active in WM9-PLX-R cells. We notice that our data is different from the previous report [40] showing that level of phosphorylated ERK remains high when the same A375-PLX-R cell line is treated with $1 \mu \mathrm{M}$ PLX4032 for $24 \mathrm{~h}$. The discrepancy may be caused by different PLX4032 concentrations and duration of treatments. Because A375-PLX-R cells were developed by gradual increase of PLX4032 concentrations up to $4 \mu \mathrm{M}$ and were maintained with medium containing $1 \mu \mathrm{M}$ PLX4032, PLX4032 at $1 \mu \mathrm{M}$ may be not sufficient to inhibit ERK phosphorylation. We also show that the dependence of Chk1 function for survival is different between PLX4032resistant lines and their parental A375 and WM9 cell lines. PF477736 is more effective in inhibiting cell viability
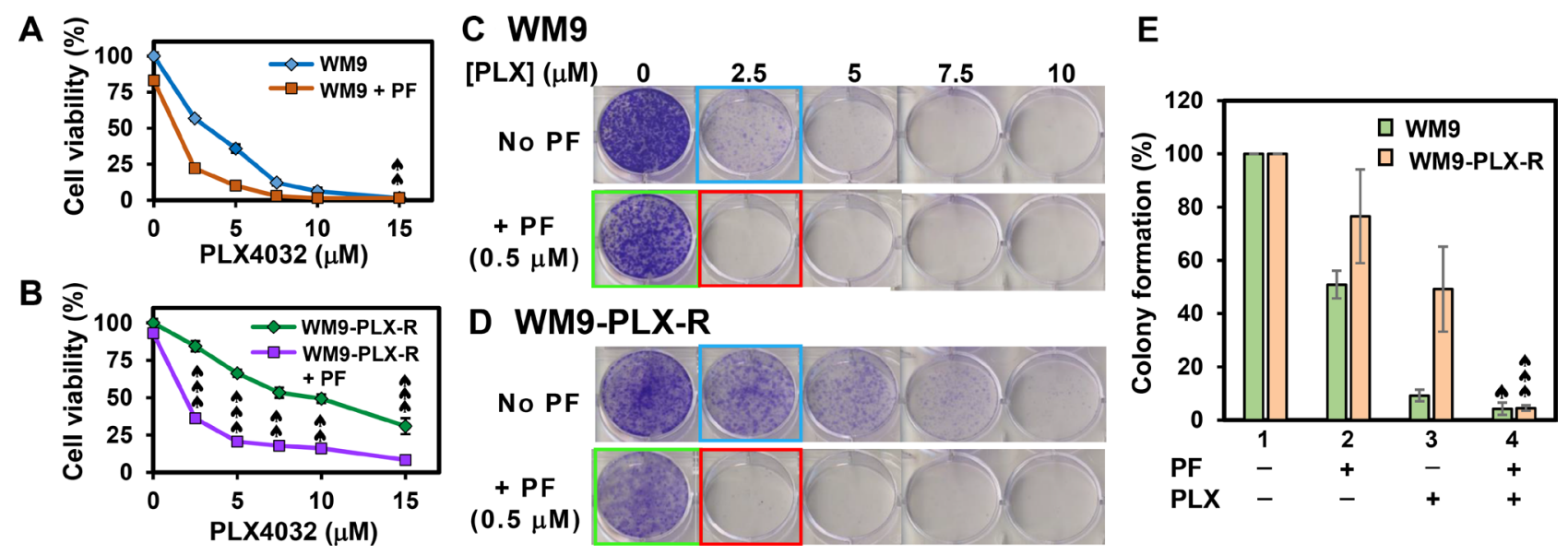

Figure 6: Cell viability and colony formation of WM9 and WM9-PLX-R cells in the presence of BRAFi PLX4032 and/ or Chk1i PF477736. The melanoma cells were treated with Chk1i (PF477736, $0.5 \mu \mathrm{M})$ in combination with increasing concentrations of BRAFi (PLX4032, 0-15 $\mu \mathrm{M}$ ) as indicated on the X-axis. Cell viability of WM9 (A) and WM9-PLX-R (B) cells as well as colony formation of WM9 (C) and WM9-PLX-R (D) cells are similar to those in Figure 4. Top panels in both (C) and (D) are cells treated with different concentrations of PLX4032 as indicated and bottom panels are cells treated with respective PLX4032 concentrations plus $0.5 \mu \mathrm{M}$ PF477736. Data from more than three experiments with $2.5 \mu \mathrm{M}$ of PLX4032 (blue boxed), $0.5 \mu \mathrm{M}$ of PF477736 (green boxed), and PLX4032 + PF477736 (red boxed) are shown in (E). The error bars, CI calculation, and symbol were similar to those as described in Figure 4. 
and colony formation of A375-PLX-R than A375 cells. However, PF477736 is more effective in inhibiting cell viability and colony formation of WM9 than WM9-PLX-R cells. Although the mechanism behind this difference requires further investigation, the different PTEN status and activation of alterative survival pathways may contribute to their differential response to Chkli treatment. It has been shown that PTEN plays a direct role in DNA damage response through interaction with Chk1 and the tumor suppressor p53 [39]. Because all four cell lines are p53 positive, the differential response to Chk1i in A375PLX-R and WM9-PLX-R is likely independent of p53, even though several studies have shown that the response to Chk1i is dependent on p53 [24, 33, 34]. Strikingly, although A375-PLX-R and WM9-PLX-R cells develop resistance to PLX4032 through different mechanisms, they re-sensitize to PLX4032 in the presence of PF477736.

To reveal why Chk1i can trigger BRAFi resistant cells regaining BRAFi sensitivity, we detect that Chk1i treatments inhibit auto-phosphorylation of Chk1 at S296 but induce hyper-phosphorylation of Chk1 at S317 and S345 which is mediated by ATR in response to DNA damage [41, 42]. The reduction of Chk1 phosphorylation at S296 in cells treated with PF477736 indicates that the inhibitor blocks Chk1 activity in vivo. Hyperphosphorylation of Chk1 at S317 and S345 has been used as an indicator of Chk1 inhibition [31, 43]. Indeed, our data indicate that the levels of Chk1 phosphorylation at S317 and S345 are reversely proportional to the level of Chk1 phosphorylation at S296 (Figure 8). It has been demonstrated that ATR-mediated Chk1 phosphorylation is antagonized by a Chk1-regulated protein phosphatase 2 A circuit [43]. Thus, when Chk1 activity is inhibited by PF477736, PP2A is inactive to dephosphorylate Chk1, leading to hyper-phosphorylation of Chk1. Combinatorial treatments with PLX4032 and PF477736 to A375, WM9, WM9-PLX-R cells for $6 \mathrm{~h}$ induce the highest levels of Chk1 S317 and S345 phosphorylation (Figure 8A and 8B). However, A375-PLX-R cells contain the highest levels of Chk1 S317 and S345 phosphorylation after combinatorial treatment with PLX4032 and PF477736 for $16 \mathrm{~h}$ but not for $6 \mathrm{~h}$ (compare Figure 8A and 8C). This suggests that A375PLX-R cells require extended Chk $1 \mathrm{i}+\mathrm{BRAFi}$ treatment to induce Chk1 hyper-phosphorylation and associated cell death as indicated with high level of cleaved PARP1 in Figure 8C. Because hypo-phosphorylation at S296 and hyper-phosphorylation at S317 and S345 of Chk1 can serve as indicators of Chk1 inhibition [31], combined treatment with PLX4032 and PF477736 is more effective than PF477736 treatment alone to inhibit Chk1 activity.

We also show that PLX4032 treatments to BRAFisensitive cells severely inhibit Chk1 S280 phosphorylation which can be mediated by two Ras downstream kinases p90 RSK [19] or AKT1 [21]. PF477736 enhances
A

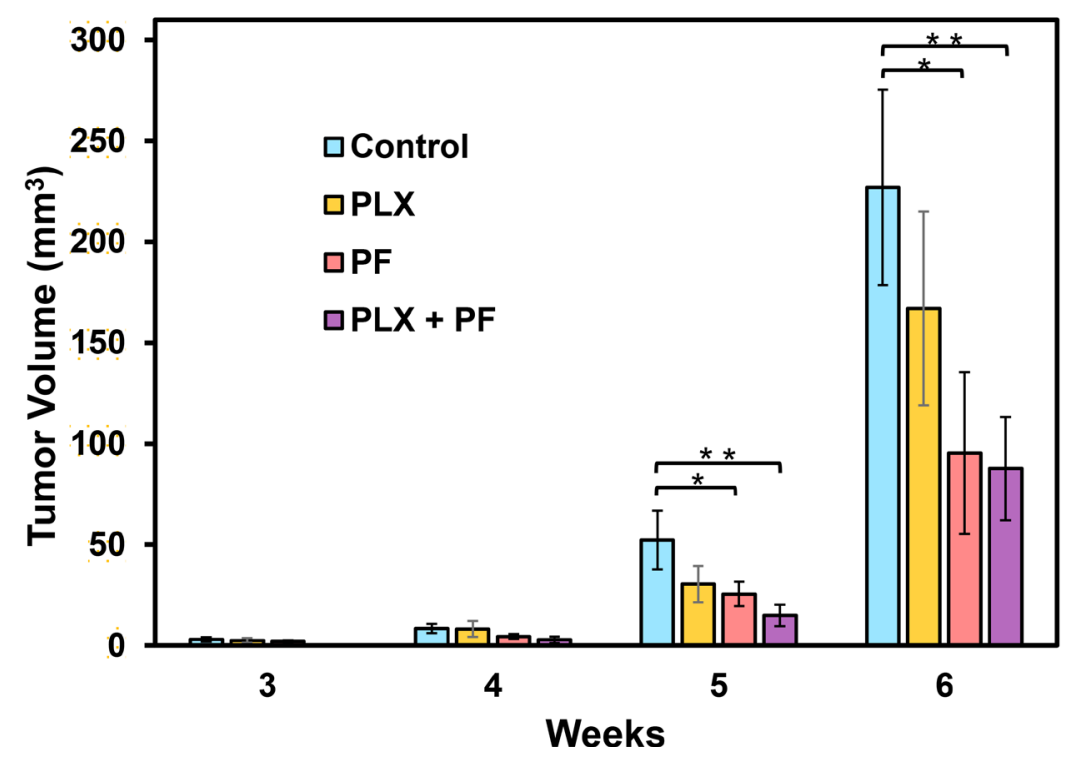

B

DMSO

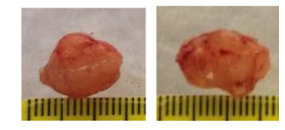

PLX4032

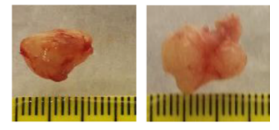

PF477736

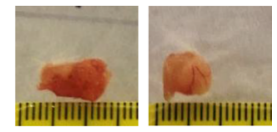

PLX + PF

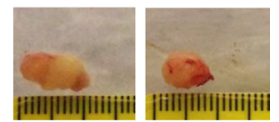

Figure 7: Chk1 inhibitor PF477736 reduces melanoma tumor growth. Tumor xenografts of A375-PLX-R melanoma spheroid cells were injected in each front flank of female nude mice. Drug treatments were initiated at the time of tumor cell injection. The mice were injected with $15 \mathrm{mg} / \mathrm{Kg}$ body weight of Chk1i (PF477736) or DMSO for three days per week and/or $20 \mathrm{mg} / \mathrm{Kg}$ body weight of PLX4032 by oral gavage. Tumor volume were measured every week. (A) The mice receiving PF477736 alone and PF477736+PLX4032, but not PLX4032 alone, have substantially smaller tumor than the controls after week 5 and week 6 with cotreatment showing more significance. The error bars reported are the standard deviations of the averages from six tumors and the $P$-value was calculated by Student's $t$-test. One star indicates $P<0.1$ and two stars indicate $P<0.05$. (B) Two representative tumors from each treatment group are shown. 
PLX4032 to inhibit Chk1 S280 phosphorylation in BRAFi-resistant cells (Figure 8). Because the levels of phosphorylated AKT are increased (Figure 2) but the levels of Chk1 S280 phosphorylation are substantially reduced (Figure 8) in PLX4032-treated A375, A375PLX-R, and WM9 cells, we suggested AKT plays limited role in Chk1 S280 phosphorylation in these melanoma cells. Synergistic effects exist with PLX4032 and PF477736 treatments in reducing the levels of total Chk1 protein and Chk1 S280 phosphorylation and increasing the levels of Chk1 S317 and S345 phosphorylation. Lee et al. [31] have found that Ras signaling engages Chk1 in a subset of osteosarcoma, ovarian, and breast cancer cells to enable their survival upon DNA damage, irrespective of

\section{A $6 h$}

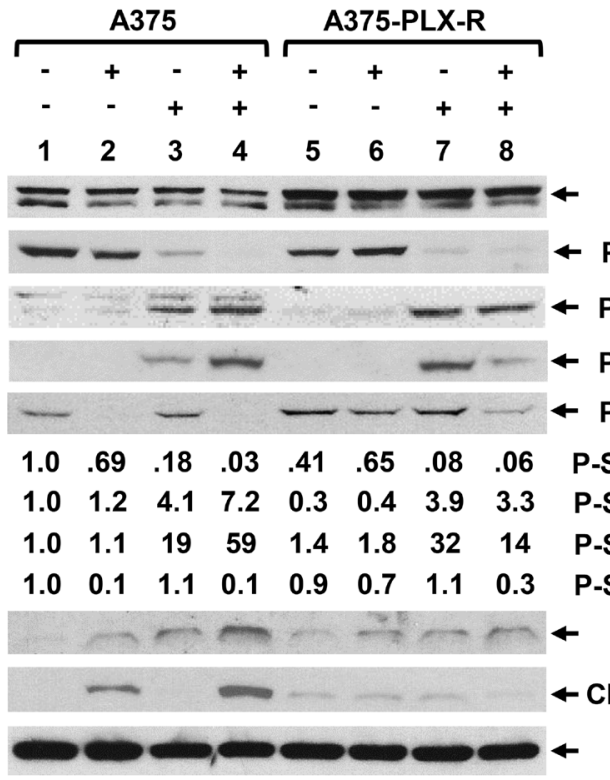

PLX 4032

PF477736

\section{B 6h}

\section{WM9}

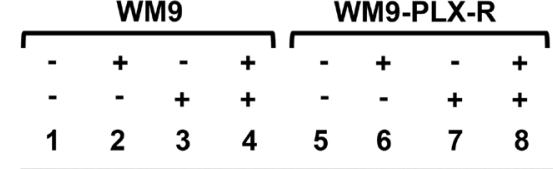

Chk1

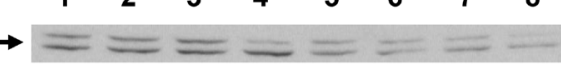

P-Chk1 (S296)

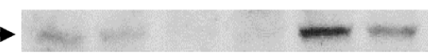

P-Chk1 (S317) $\rightarrow$

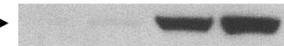

-Chk1 (S345)

$\rightarrow$

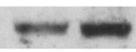

P-Chk1 (S280)

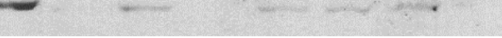

P-S317/Chk1 ratio

$\begin{array}{llllllll}1.0 & .72 & .21 & .36 & 7.6 & 4.3 & .35 & .08\end{array}$

-S345/Chk1 ratio

$\begin{array}{llllllll}1.0 & 1.3 & 59 & 85 & 0.6 & 0.8 & 17 & 53\end{array}$

-S280/Chk1 ratio

$\begin{array}{llllllll}1.0 & 1.0 & 39 & 78 & 1.9 & 2.4 & 15 & 179\end{array}$

$\begin{array}{llllllll}1.0 & 0.1 & 0.3 & 0.0 & 0.5 & 0.7 & 0.7 & 0.1\end{array}$

Actin

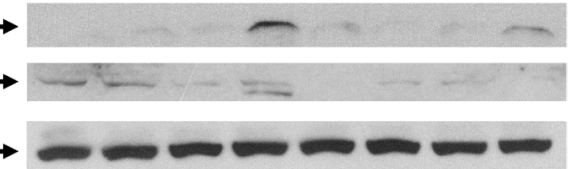

C 16h

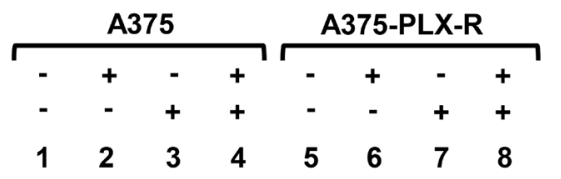

PLX 4032

PF477736
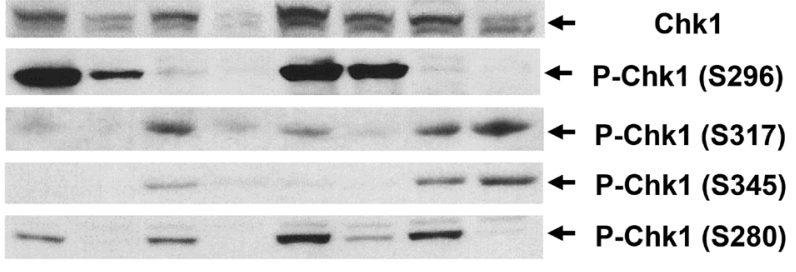

$\begin{array}{lllllllll}1.0 & .42 & .05 & .05 & .66 & .76 & .04 & .02 & \text { P-S296/Chk1 ratio }\end{array}$

$\begin{array}{lllllllll}1.0 & 1.1 & 5.9 & 3.7 & 1.7 & 0.5 & 4.4 & 9.9 & \text { P-S317/Chk1 ratio }\end{array}$

$\begin{array}{lllllllll}1.0 & 1.5 & 9.4 & 14 & 2.7 & 3.5 & 13 & 33 & \text { P-S345/Chk1 ratio }\end{array}$

$\begin{array}{lllllllll}1.0 & 0.1 & 1.3 & 0.1 & 1.8 & 0.6 & 1.9 & 0.1 & \text { P-S280/Chk1 ratio }\end{array}$

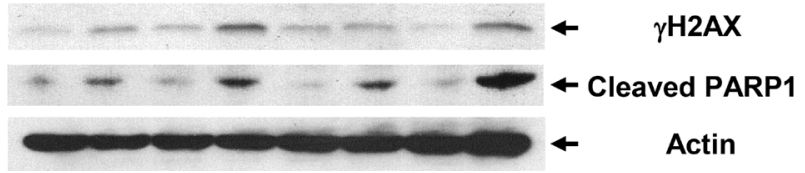

Figure 8: Expression of DNA damage response proteins in melanoma cells following treatments with BRAFi and/or Chk1i. Cells were treated with PLX4032 $(7.5 \mu \mathrm{M})$ and/or PF477736 $(0.15 \mu \mathrm{M})$ for $6 \mathrm{~h}$ or $16 \mathrm{~h}$. (A) A375 and A375-PLX-R cells treated with drugs for $6 \mathrm{~h}$; (B) WM9 and WM9-PLX-R cells treated with drugs for $6 \mathrm{~h}$; and (C) A375 and A375-PLX-R cells treated with drugs for $16 \mathrm{~h}$. Western blotting analyses with respective antibodies were performed. Ratios of phosphorylated Chk1 proteins at S296, S317, S345, or S280 over total Chk1 protein were calculated and then adjusted relative to the value of lane 1 (untreated A375 or WM9 cells) as described in Figure 2. Relative ratios are the averages of two sets of images from two independent experiments. 
p53 mutation status. The authors demonstrated a feedback mechanism between Ras signaling and Chk1 function: Ras drives Chk1 expression and Chk1 prevents hyper-activation of Ras signaling to sustain cancer cell proliferation. Thus, we suggest that the synergistic effects of combinatorial PLX4032 and PF477736 treatments on Chk1 expression and phosphorylation may perturb cell cycle progression, induce DNA damage, and lead to cell death.

The above scenario is supported by the elevated levels of $\gamma \mathrm{H} 2 \mathrm{AX}$ and cleaved PARP1 in A375 cells treated with PLX4032+PF477736. Although the level of $\gamma \mathrm{H} 2 \mathrm{AX}$ is high but the level of cleaved PARP1 does not increased when A375-PLX-R, WM9, and WM9-PLX-R cells are treated with PLX4032+PF477736 for $6 \mathrm{~h}$. PARP1 cleavage is induced in A375-PLX-R cells only after $16 \mathrm{~h}$ treatments with PLX4032 and PLX4032+PF477736. This implies that A375PLX-R cells require extended treatments with PLX4032 and PLX4032+PF477736 to induce caspase-dependent apoptosis. PF477736 treatments to A375 for $6 \mathrm{~h}$ and A375PLX-R cells for $16 \mathrm{~h}$ does not induce PARP cleavage, but can potentiate the stimulation action of PLX4032 on PARP1 cleavage (Figure 8A and 8C). Because PF477736 treatment alone reduces cell viability and colony formation of all four cell lines (Figure 3), we suggest that PF477736 may induce caspase-independent cell death pathways [47]. Our result is similar to the findings that Chk1i do not increase the levels of $\gamma \mathrm{H} 2 \mathrm{AX}$ and activated caspase 3 in K-Ras-induced pancreatic adenocarcinomas [48]. However, Chk1 has been shown to suppress caspase-dependent apoptotic pathways $[49,50]$ and PARP cleavage is detected in melanoma cells treated with Chk1 inhibitor AR323 for longer than $24 \mathrm{~h}$ [32]. In conclusion, our results indicate that combinatorial treatment with PLX4032 and PF477736 promotes DNA damage and may induce different pathways of cell death in melanoma cells.

Although the mechanisms by which Chk1 inhibitors boost BRAFi sensitivity in BRAFi-resistant melanoma still need further clarification, our results support a model that Chk1 inhibition in combination with BRAFi can lead melanoma cells to arrest improperly, enter into mitosis with highly damaged DNA, and undergo mitotic catastrophe/cell death (Figure 9). This model has been suggested in combinatorial treatments of Chk1i with DNA damaging agents to cancer cells $[32,51]$. Cancer cells induce moderate DNA damage response to manage Rasinduced DNA damage and replication stress. The levels of total Chk1 and Chk1 phosphorylation at S280 and S296 are high, while the levels of Chk1 phosphorylation at S317 and S345 are low. In the presence of Chk1i and BRAFi, cancer cells contain high levels of damaged DNA and replicative stress but lose cell cycle checkpoints. The levels of total Chk1 and Chk1 phosphorylation at S280 and S296 are decreased, but the levels of Chk1 phosphorylation at S317 and S345 are increased. Our work suggests that combinatorial therapies with Chk1i and BRAFi will improve the outcomes and curtail the resistance to BRAFi in melanoma.

\section{MATERIALS AND METHODS}

\section{Melanoma cell lines and culture}

A375 and its PLX4032-resistant cell lines were maintained under attached conditions in growth media

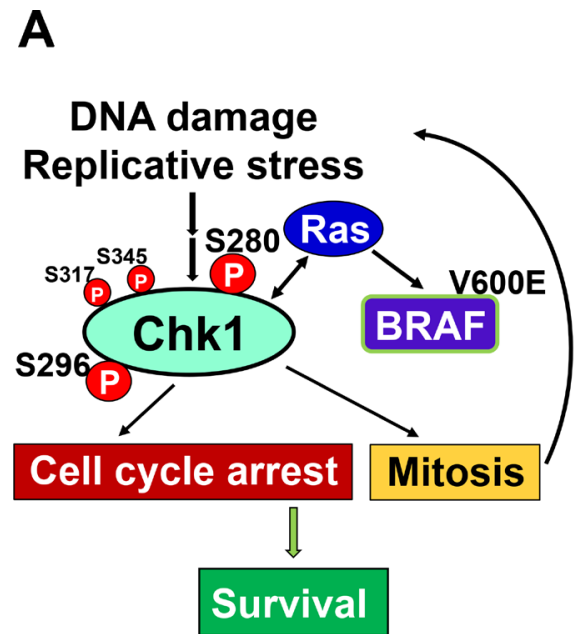

B

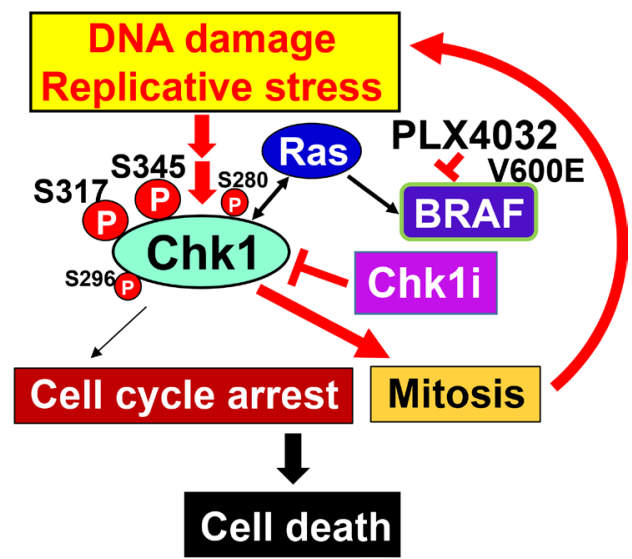

Figure 9: Model for Chk1 regulation of cancer cell survival. (A) Cancer cells use DNA damage response to manage Rasinduced DNA damage and replication stress. Ras and Chk1 use feedback pathways to minimalize DNA damage, maintain moderate cell cycle arrest, and sustain cell proliferation. The levels of total Chk1 and Chk1 phosphorylation at S280 and S296 are high, while the levels of Chk1 phosphorylation at S317 and S345 are low. (B) Chk1i in combination with BRAFi could lead cancer cells to arrest improperly, enter into mitosis with highly damaged DNA, and undergo apoptosis. Inhibition of Chk1 can decrease the levels of total Chk1 and Chk1 phosphorylation at S280 and S296, but increase Chk1 phosphorylation at S317 and S345. 
containing DMEM (Invitrogen, Frederick, MD, USA) supplemented with $4.5 \mathrm{mg} / \mathrm{ml}$ D-glucose, $2 \mathrm{mM}$ L-glutamine, $1 \mathrm{mM}$ sodium pyruvate, and 5\% fetal calf serum. WM9 and its PLX4032-resistant cell lines were grown in 2\% Tumor Medium (Tu2\%) containing a 4:1 mixture of MCDB 153 medium and Leibovitz's L15 medium supplemented with $0.005 \mathrm{mg} / \mathrm{ml}$ bovine insulin, $1.68 \mathrm{mM} \mathrm{CaCl}_{2}$, and $\%$ fetal bovine serum. PLX4032resistant A375-PLX-R cell line has been created by gradual increase of PLX4032 up to $4 \mu \mathrm{M}$ as reported [40]. WM9-PLX-R cell line was derived from WM9 cell line similarly according to the procedure described [40]. Briefly, cells were treated with $1 \mu \mathrm{M}$ PLX4032 in monolayer culture in growth medium for several weeks. The surviving cells were then expanded and cultured in increasing doses of PLX4032 up to $4 \mu \mathrm{M}$. The resulting PLX4032-resistant cells were routinely maintained with media containing $1 \mu \mathrm{M}$ PLX4032. Spheroid melanoma cells were derived from monolayer cultures as described previously [40].

\section{Western blotting}

These antibodies used for Western blotting were purchased from Cell Signaling Technology: ERK1/2, T202Y204 phosphorylated ERK1/2, AKT, S473 phosphorylated AKT, S296 phosphorylated Chk1, S317 phosphorylated Chk1, S345 phosphorylated Chk1, $\gamma \mathrm{H} 2 \mathrm{AX}$, and cleaved PARP. Antibody of Chk1 is from Bethyl Laboratories Inc. Antibodies of $\beta$-actin and horseradish peroxidase-conjugated anti-mouse/antirabbit antibodies are from Sigma-Aldrich and Bio-Rad, respectively. Cell extracts were prepared as described [52] and about $25 \mu \mathrm{g}$ of total protein were separated on $10-16 \%$ SDS-polyacrylamide gels and transferred to nitrocellulose membranes for Western blotting [52]. To calculate the ratios of phosphorylated proteins over total proteins, the images from the X-ray films were scanned and quantitated by ImageQaunt software (GE Healthcare Life Sciences). After subtracting the background, the calculated ratios were then adjusted relative to the ratio value of untreated A375 cells.

\section{Cell viability and colony formation assays}

Cell viability was measured using the neutral red uptake assay [53]. Melanoma cells were seeded in 12-well flat bottom tissue culture plates. One-day post-seeding, the cells were treated with PLX4032 (APEXBIO), PF477736 (Sigma-Aldrich), or DMSO for $48 \mathrm{~h}$. The cells were then recovered in regular media for 2-3 days. The plates were incubated for $2 \mathrm{~h}$ in regular medium containing $40 \mu \mathrm{g} / \mathrm{ml}$ of neutral red (3-amino-7-dimethylamino-2-methylphenazine hydrochloride, Sigma). After the cells being washed with PBS, the dye was extracted from each well with acidified ethanol solution and the absorbance at
$540 \mathrm{~nm}$ was read by a Multiskan Spectrum microplate spectrometer (Thermo Lab systems).

For clonogenic survival assays, cells were seeded at 5000 cells per well in 6-well plates and treated with drugs as described above. Regular media was replaced after treatment. After 10 days, cells were stained with $0.5 \%$ crystal violet in $20 \%$ methanol and counted.

Combination index (CI) for cells treated with two drugs was determined by CompuSyn software for the Chou and Talalay analysis as described [54]. A CI value less than 1 indicates synergic effect.

\section{Tumor xenograft studies}

Cells were grown for ten days as spheroids and a single cell suspension, prepared by trypsin digestion, was resuspended in phosphate buffered saline containing 30\% Matrigel and $100 \mu \mathrm{l}$ containing 0.1 million cells were injected subcutaneously at the two front flanks of NOD/ scid/IL2 receptor gamma-knockout mice (NSG mice) using a 26.5-gauge needle. Three mice were used per data point with two tumors per mouse. PLX4032 was dissolved in PBS containing 10\% DMSO and $100 \mu \mathrm{l}$ was delivered by oral gavage $(20 \mathrm{mg} / \mathrm{Kg}$ body weight) three times per week $(\mathrm{M} / \mathrm{W} / \mathrm{F})$ beginning at the time of tumor cell injection. PF477736 dissolved in DMSO was mixed with 40\% PEG 400 in PBS and Tween 80 at 2:97:1 ratio and $15 \mathrm{mg} / \mathrm{Kg}$ was delivered by intraperitoneal injection three times per week $(\mathrm{M} / \mathrm{W} / \mathrm{F})$. Tumor growth was monitored by measuring tumor diameter and calculating tumor volume

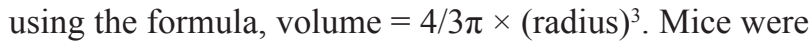
euthanized by injecting $250 \mu \mathrm{l}$ of a $2.5 \%$ stock of avertin per mouse followed by cervical dislocation, and tumor samples were harvested for morphological assessment. These experiments were reviewed and approved by the University of Maryland-Baltimore Institutional Animal Care and Use Committee.

\section{Abbreviations}

A375-PLX-R cell line: a PLX4032 resistant cell line from A375; AKT/PKB: protein kinase B; ATR: ataxia telangiectasia and Rad3-related protein; BRAF: v-Raf murine sarcoma viral oncogene homolog B1; BRAFi: BRAF inhibitors; CI: combination index; Chki: Chk1 inhibitors; ERK: extracellular signal-regulated kinase; HR: hazard ratio; $\mathrm{IC}_{50}$ : the concentration of drug to inhibit $50 \%$ of cell growth; MEK: mitogen-activated protein kinase; MCS: melanoma cancer stem cell; p90 RSK: Ras/ mitogen-activated 90-kDa ribosomal S6 kinase; PI3K: phosphatidylinositol 3-kinase; PDK1:3-phosphoinositidedependent protein kinase-1; PF477736: a specific inhibitor of Chk1; PLX4032 (Vemurafenib): a specific BRAF inhibitor; PTEN: phosphatase and tensin homology; $\mathrm{T}_{1 / 2}$ : the time required for $50 \%$ of the patients remain alive; $\Delta \mathrm{T}_{1 / 2}$ : the difference between two $\mathrm{T}_{1 / 2(\mathrm{~s})}$ for each group 
of patients. V600E mutation: residue 600 Valine to Asparagine mutation; WM9-PLX-R cell line: a PLX4032 resistant cell line from WM9; $\gamma \mathrm{H} 2 \mathrm{AX}$ : phosphorylated histone H2AX.

\section{Author contributions}

Bor-Jang Hwang developed WM9-PLX-R cell line and performed Western blotting, cell viability, and colony formation assays. Gautam Adhikary and Bor-Jang Hwang isolated melanoma spheroid cells and performed the mouse xenograft experiments. Richard Eckert supervised the mouse xenograft experiments. A-Lien Lu conceived the work and assisted in experimental design and preparation of the paper. All authors read and approved the final manuscript.

\section{ACKNOWLEDGMENTS}

We thank Drs. Daniel Grun and Matthew Fisher for helping the mouse experiments and developing the PLX4032 resistance cell lines, respectively. We also thank Dr. David Kaetzel for providing WM9 cell.

\section{CONFLICTS OF INTEREST}

The authors declare no conflicts of interest.

\section{FUNDING}

This work was supported by National Institutes of Health grants R01GM118837 to A-Lien Lu as well as R01-CA184027 and R01-CA211909 to Richard Eckert.

\section{REFERENCES}

1. Chudnovsky Y, Khavari PA, Adams AE. Melanoma genetics and the development of rational therapeutics. J Clin Invest. 2005; 115:813-24. https://doi.org/10.1172/JCI24808.

2. Davies MA, Samuels Y. Analysis of the genome to personalize therapy for melanoma. Oncogene. 2010; 29:5545-55. https://doi.org/10.1038/onc.2010.323.

3. Shapiro P. Ras-MAP kinase signaling pathways and control of cell proliferation: relevance to cancer therapy. Crit Rev Clin Lab Sci. 2002; 39:285-330.

4. Goel VK, Lazar AJ, Warneke CL, Redston MS, Haluska FG. Examination of mutations in BRAF, NRAS, and PTEN in primary cutaneous melanoma. J Invest Dermatol. 2006; 126:154-60. https://doi.org/10.1038/sj.jid.5700026.

5. Haluska FG, Tsao H, Wu H, Haluska FS, Lazar A, Goel $\mathrm{V}$. Genetic alterations in signaling pathways in melanoma. Clin Cancer Res. 2006; 12:2301s-7s. https://doi. org/10.1158/1078-0432.CCR-05-2518.
6. Dankort D, Curley DP, Cartlidge RA, Nelson B, Karnezis AN, Damsky WE Jr, You MJ, DePinho RA, McMahon M, Bosenberg M. Braf(V600E) cooperates with Pten loss to induce metastatic melanoma. Nat Genet. 2009; 41:544-52. https://doi.org/10.1038/ng.356.

7. Menzies AM, Long GV. Systemic treatment for BRAFmutant melanoma: where do we go next? Lancet Oncol. 2014; 15:e371-81. https://doi.org/10.1016/S1470-2045(14)70072-5.

8. Bollag G, Tsai J, Zhang J, Zhang C, Ibrahim P, Nolop K, Hirth P. Vemurafenib: the first drug approved for BRAFmutant cancer. Nat Rev Drug Discov. 2012; 11:873-86. https://doi.org/10.1038/nrd3847.

9. Hartsough E, Shao Y, Aplin AE. Resistance to RAF inhibitors revisited. J Invest Dermatol. 2014; 134:319-25. https://doi.org/10.1038/jid.2013.358.

10. Sosman JA, Kim KB, Schuchter L, Gonzalez R, Pavlick AC, Weber JS, McArthur GA, Hutson TE, Moschos SJ, Flaherty KT, Hersey P, Kefford R, Lawrence D, et al. Survival in BRAF V600-mutant advanced melanoma treated with vemurafenib. N Engl J Med. 2012; 366:707-14. https://doi.org/10.1056/NEJMoa1112302.

11. Sancar A, Lindsey-Boltz LA, Unsal-Kacmaz K, Linn S. Molecular mechanisms of mammalian DNA repair and the DNA damage checkpoints. Annu Rev Biochem. 2004; 73:39-85. https://doi.org/10.1146/annurev. biochem.73.011303.073723.

12. Bartek J, Lukas C, Lukas J. Checking on DNA damage in S phase. Nat Rev Mol Cell Biol. 2004; 5:792-804. https://doi.org/10.1038/nrm1493.

13. Matsuoka S, Ballif BA, Smogorzewska A, McDonald ER III, Hurov KE, Luo J, Bakalarski CE, Zhao Z, Solimini N, Lerenthal Y, Shiloh Y, Gygi SP, Elledge SJ. ATM and ATR substrate analysis reveals extensive protein networks responsive to DNA damage. Science. 2007; 316:1160-6. https://doi.org/10.1126/science.1140321.

14. Niida H, Katsuno Y, Banerjee B, Hande MP, Nakanishi M. Specific role of Chk1 phosphorylations in cell survival and checkpoint activation. Mol Cell Biol. 2007; 27:2572-81. https://doi.org/10.1128/MCB.01611-06.

15. Clarke CA, Clarke PR. DNA-dependent phosphorylation of Chk1 and Claspin in a human cell-free system. Biochem J. 2005; 388:705-12. https://doi.org/10.1042/BJ20041966.

16. Kasahara K, Goto H, Enomoto M, Tomono Y, Kiyono T, Inagaki M. 14-3-3gamma mediates Cdc25A proteolysis to block premature mitotic entry after DNA damage. EMBO J. 2010; 29:2802-12. https://doi.org/10.1038/emboj.2010.157.

17. Goto H, Kasahara K, Inagaki M. Novel insights into Chk1 regulation by phosphorylation. Cell Struct Funct. 2015; 40:43-50. https://doi.org/10.1247/csf.14017.

18. Zhang Y, Hunter T. Roles of Chk1 in cell biology and cancer therapy. Int J Cancer. 2014; 134:1013-23. https:// doi.org/10.1002/ijc.28226. 
19. Li P, Goto H, Kasahara K, Matsuyama M, Wang Z, Yatabe Y, Kiyono T, Inagaki M. P90 RSK arranges Chk1 in the nucleus for monitoring of genomic integrity during cell proliferation. Mol Biol Cell. 2012; 23:1582-92. https://doi. org/10.1091/mbc.E11-10-0883.

20. King FW, Skeen J, Hay N, Shtivelman E. Inhibition of Chk1 by activated PKB/Akt. Cell Cycle. 2004; 3:634-7.

21. Puc J, Keniry M, Li HS, Pandita TK, Choudhury AD, Memeo L, Mansukhani M, Murty VV, Gaciong Z, Meek SE, Piwnica-Worms H, Hibshoosh H, Parsons R. Lack of PTEN sequesters CHK1 and initiates genetic instability. Cancer Cell. 2005; 7:193-204. https://doi.org/10.1016/j. ccr.2005.01.009.

22. Shtivelman E, Sussman J, Stokoe D. A role for PI 3-kinase and PKB activity in the G2/M phase of the cell cycle. Curr Biol. 2002; 12:919-24.

23. Lapenna S, Giordano A. Cell cycle kinases as therapeutic targets for cancer. Nat Rev Drug Discov. 2009; 8:547-66. https://doi.org/10.1038/nrd2907.

24. McNeely S, Beckmann R, Bence Lin AK. CHEK again: revisiting the development of CHK1 inhibitors for cancer therapy. Pharmacol Ther. 2014; 142:1-10. https://doi. org/10.1016/j.pharmthera.2013.10.005.

25. Al-Kaabi MM, Alshareeda AT, Jerjees DA, Muftah AA, Green AR, Alsubhi NH, Nolan CC, Chan S, Cornford E, Madhusudan S, Ellis IO, Rakha EA. Checkpoint kinase1 (CHK1) is an important biomarker in breast cancer having a role in chemotherapy response. Br J Cancer. 2015; 112: 901-11. https://doi.org/10.1038/bjc.2014.576.

26. Albiges L, Goubar A, Scott V, Vicier C, Lefebvre C, Alsafadi S, Commo F, Saghatchian M, Lazar V, Dessen P, Delaloge S, Andre F, Quidville V. Chk1 as a new therapeutic target in triple-negative breast cancer. Breast. 2014; 23: 250-8. https://doi.org/10.1016/j.breast.2014.02.004.

27. Bryant C, Rawlinson R, Massey AJ. Chk1 inhibition as a novel therapeutic strategy for treating triple-negative breast and ovarian cancers. BMC Cancer. 2014; 14: 570. https:// doi.org/10.1186/1471-2407-14-570.

28. Shibata H, Miuma S, Saldivar JC, Huebner K. Response of subtype-specific human breast cancer-derived cells to poly(ADP-ribose) polymerase and checkpoint kinase 1 inhibition. Cancer Sci. 2011; 102:1882-8. https://doi. org/10.1111/j.1349-7006.2011.02016.x.

29. Rundle S, Bradbury A, Drew Y, Curtin NJ. Targeting the ATR-CHK1 Axis in Cancer Therapy. Cancers (Basel). 2017; 9:41. https://doi.org/10.3390/cancers9050041.

30. Blasina A, Hallin J, Chen E, Arango ME, Kraynov E, Register J, Grant S, Ninkovic S, Chen P, Nichols T, O'Connor $\mathrm{P}$, Anderes K. Breaching the DNA damage checkpoint via PF-00477736, a novel small-molecule inhibitor of checkpoint kinase 1. Mol Cancer Ther. 2008; 7:2394-404. https://doi. org/10.1158/1535-7163.MCT-07-2391.

31. Lee HJ, Cao Y, Pham V, Blackwood E, Wilson C, Evangelista M, Klijn C, Stokoe D, Settleman J. Ras-MEK Signaling Mediates a Critical Chk1-Dependent DNA Damage
Response in Cancer Cells. Mol Cancer Ther. 2017; 16: 694-704. https://doi.org/10.1158/1535-7163.MCT-16-0504.

32. Brooks K, Oakes V, Edwards B, Ranall M, Leo P, Pavey S, Pinder A, Beamish H, Mukhopadhyay P, Lambie D, Gabrielli B. A potent Chk1 inhibitor is selectively cytotoxic in melanomas with high levels of replicative stress. Oncogene. 2013; 32:788-96. https://doi.org/10.1038/onc.2012.72.

33. Vera J, Raatz Y, Wolkenhauer O, Kottek T, Bhattacharya A, Simon JC, Kunz M. Chk1 and Wee1 control genotoxic-stress induced G2-M arrest in melanoma cells. Cell Signal. 2015; 27:951-60. https://doi.org/10.1016/j.cellsig.2015.01.020.

34. Xiao Y, Ramiscal J, Kowanetz K, Del Nagro C, Malek S, Evangelista M, Blackwood E, Jackson PK, O'Brien T. Identification of preferred chemotherapeutics for combining with a CHK1 inhibitor. Mol Cancer Ther. 2013; 12:228595. https://doi.org/10.1158/1535-7163.MCT-13-0404.

35. Aguirre-Gamboa R, Gomez-Rueda H, Martinez-Ledesma E, Martinez-Torteya A, Chacolla-Huaringa R, RodriguezBarrientos A, Tamez-Pena JG, Trevino V. SurvExpress: an online biomarker validation tool and database for cancer gene expression data using survival analysis. PLoS One. 2013; 8:e74250. https://doi.org/10.1371/journal.pone.0074250.

36. Paraiso KH, Xiang Y, Rebecca VW, Abel EV, Chen YA, Munko AC, Wood E, Fedorenko IV, Sondak VK, Anderson AR, Ribas A, Palma MD, Nathanson KL, et al. PTEN loss confers BRAF inhibitor resistance to melanoma cells through the suppression of BIM expression. Cancer Res. 2011; 71:2750-60. https://doi.org/10.1158/0008-5472. CAN-10-2954.

37. Abbotts R, Jewell R, Nsengimana J, Maloney DJ, Simeonov A, Seedhouse C, Elliott F, Laye J, Walker C, Jadhav A, Grabowska A, Ball G, Patel PM, et al. Targeting human apurinic/apyrimidinic endonuclease 1 (APE1) in phosphatase and tensin homolog (PTEN) deficient melanoma cells for personalized therapy. Oncotarget. 2014; 5:3273-86. https://doi.org/10.18632/oncotarget.1926.

38. Bassi C, Ho J, Srikumar T, Dowling RJ, Gorrini C, Miller SJ, Mak TW, Neel BG, Raught B, Stambolic V. Nuclear PTEN controls DNA repair and sensitivity to genotoxic stress. Science. 2013; 341:395-9. https://doi.org/10.1126/ science. 1236188.

39. Ming M, He YY. PTEN in DNA damage repair. Cancer Lett. 2012; 319:125-9. https://doi.org/10.1016/j.canlet.2012.01.003.

40. Fisher ML, Grun D, Adhikary G, Xu W, Eckert RL. Inhibition of YAP function overcomes BRAF inhibitor resistance in melanoma cancer stem cells. Oncotarget. 2017; 8:110257-72. https://doi.org/10.18632/oncotarget.22628.

41. Liu Q, Guntuku S, Cui XS, Matsuoka S, Cortez D, Tamai K, Luo G, Carattini-Rivera S, DeMayo F, Bradley A, Donehower LA, Elledge SJ. Chk1 is an essential kinase that is regulated by Atr and required for the G(2)/M DNA damage checkpoint. Genes Dev. 2000; 14:1448-59.

42. Zhao H, Piwnica-Worms H. ATR-mediated checkpoint pathways regulate phosphorylation and activation of human 
Chk1. Mol Cell Biol. 2001; 21:4129-39. https://doi.org/ 10.1128/MCB.21.13.4129-4139.2001.

43. Leung-Pineda V, Ryan CE, Piwnica-Worms $H$. Phosphorylation of Chk1 by ATR is antagonized by a Chk1regulated protein phosphatase $2 \mathrm{~A}$ circuit. Mol Cell Biol. 2006; 26:7529-38. https://doi.org/10.1128/MCB.00447-06.

44. Firsanov DV, Solovjeva LV, Svetlova MP. H2AX phosphorylation at the sites of DNA double-strand breaks in cultivated mammalian cells and tissues. Clin Epigenetics. 2011; 2:283-97. https://doi.org/10.1007/ s13148-011-0044-4.

45. Kuo LJ, Yang LX. Gamma-H2AX - a novel biomarker for DNA double-strand breaks. In Vivo. 2008; 22:305-9.

46. Kaufmann SH, Desnoyers S, Ottaviano Y, Davidson NE, Poirier GG. Specific proteolytic cleavage of poly(ADPribose) polymerase: an early marker of chemotherapyinduced apoptosis. Cancer Res. 1993; 53:3976-85.

47. Kroemer G, Martin SJ. Caspase-independent cell death. Nat Med. 2005; 11:725-30. https://doi.org/10.1038/nm1263.

48. Murga M, Campaner S, Lopez-Contreras AJ, Toledo LI, Soria R, Montana MF, Artista L, Schleker T, Guerra C, Garcia E, Barbacid M, Hidalgo M, Amati B, et al. Exploiting oncogene-induced replicative stress for the selective killing of Myc-driven tumors. Nat Struct Mol Biol. 2011; 18:1331-5. https://doi.org/10.1038/nsmb.2189.

49. Myers K, Gagou ME, Zuazua-Villar P, Rodriguez R, Meuth M. ATR and Chk1 suppress a caspase-3-dependent apoptotic response following DNA replication stress. PLoS Genet. 2009; 5:e1000324. https://doi.org/10.1371/journal. pgen. 1000324.

50. Sidi S, Sanda T, Kennedy RD, Hagen AT, Jette CA, Hoffmans R, Pascual J, Imamura S, Kishi S, Amatruda JF, Kanki JP, Green DR, D'Andrea AA, et al. Chk1 suppresses a caspase-2 apoptotic response to DNA damage that bypasses p53, Bcl-2, and caspase-3. Cell. 2008; 133: 864-77. https://doi.org/10.1016/j.cell.2008.03.037.

51. Ma CX, Janetka JW, Piwnica-Worms H. Death by releasing the breaks: CHK1 inhibitors as cancer therapeutics. Trends Mol Med. 2011; 17:88-96. https://doi.org/10.1016/j. molmed.2010.10.009.

52. Hwang BJ, Shi G, Lu AL. Mammalian MutY homolog (MYH or MUTYH) protects cells from oxidative DNA damage. DNA Repair (Amst). 2014; 13:10-21. https://doi. org/10.1016/j.dnarep.2013.10.011.

53. Repetto G, del Peso A, Zurita JL. Neutral red uptake assay for the estimation of cell viability/cytotoxicity. Nat Protoc. 2008; 3:1125-31. https://doi.org/10.1038/nprot.2008.75.

54. Chou TC. Drug combination studies and their synergy quantification using the Chou-Talalay method. Cancer Res. 2010; 70:440-6. https://doi.org/10.1158/0008-5472. CAN-09-1947. 